\title{
Neurological Changes after Surgical Intervention for Intrinsic Cavernous Angioma
}

\author{
Takafumi Nishizaki, Norio Ikeda, Shigeki Nakano, Tomomi Okamura, Takanori Sakakura \\ Department of Neurosurgery, Ube Industries Central Hospital, Ube, Japan \\ Email: nishiza@jean.ocn.ne.jp
}

Received May 10, 2012; revised June 25, 2012; accepted July 27, 2012

\begin{abstract}
We report neurological changes and circulatory and pulmonary symptoms after surgical intervention in cases of brainstem cavernous angioma. Eight patients who underwent surgical intervention for brainstem cavernous angiomas were retrospectively reviewed. Two of 4 patients who underwent total removal of the mass showed marked resolution of the preoperative signs including IX nerve palsy, MLF syndrome, cerebellar sign and homonymous hemianopsia, and two patients who underwent partial removal of the lesions had permanent neurological deficits. Inadequate excision results in not only recurrence of hemorrhage, but also postoperative neurological deterioration. Bradycardia can occur during the surgical intervention, and careful monitoring is mandatory for a couple of days after operation to detect circulatory and pulmonary failure such as atrial flutter.
\end{abstract}

Keywords: Surgical Intervention; Brainstem Cavernous Angioma; Postoperative Neurological Changes; Circulatory and Pulmonary Symptoms

\section{Introduction}

The surgical approach for intrinsic brainstem lesions is one of the most difficult forms of intervention in the neurosurgical field. Cavernous angioma with hemorrhagic events is the most obvious indication for complete resection $[1,2]$.

While postoperative neurological deterioration is negligible after surgical treatment for such intrinsic brainstem lesions, little is known about postoperative neurological deficits and changes in vital signs in the short or long term. In this study, we investigated postoperative neurological changes and intraoperative and postoperative changes in circulatory dynamics and pulmonary symptoms in patients with brainstem cavernous angioma.

\section{Clinical Materials and Methods}

We retrospectively reviewed our clinical experience with cases of cavernous angioma treated surgically between 1990 and 2011. Medical and surgical records and radiographs were reviewed. The average age of the patients was 54.5 years, and 5 patients were female. Surgical approaches were determined according to the point where the angioma and hematoma are closest to the brainstem surface. Middline suboccipital (2 patients) and lateral suboccipital (1 patient) approaches were performed in patients with pontine lesion. Two patients with medulla angioma underwent midline suboccipital approach. Sub- temporal (2 patients) and occipital transtentorial (1 patient) approaches were performed in patients with midbrain angioma. Total and subtotal removal was performed for 4 and 2 cavernous angiomas, respectively. Partial removal was performed in 2 patients. Postoperative neurological changes were evaluated at about one week after surgery and at discharge. Intraoperative and postoperative changes in circulatory dynamics and pulmonary disease were also evaluated. In recent cases, intraoperative monitoring was performed if necessary, including the facial nerve, abducens nerve, motor evoked potential (MEP) and auditory brainstem response (ABR) in conjunction with navigation system and intraoperative ultrasonography.

\section{Results}

Four of the 8 patients with cavernous angiomas underwent total removal of the mass (Table 1). Two showed no neurological deterioration after surgery. One patient who underwent total removal of a cavernous angioma in the medulla oblongata showed marked resolution of preoperative swallowing disturbance and cerebellar symptoms and medial longitudinal fasciculus (MLF) immediately after the operation (Figure 1). One patient who underwent subtotal removal of the mass in the pons via lateral suboccipital approach, showed gradual improvement of facial function and cerebellar symptoms. Two patients showed temporary worsening of symptoms 
Table 1. Summary of 8 cases of brainstem cavernous angioma.

\begin{tabular}{|c|c|c|c|c|c|c|c|c|c|c|}
\hline No & $\begin{array}{c}\text { Age } \\
\text { gender }\end{array}$ & Location & $\begin{array}{l}\text { Operation } \\
\text { mode }\end{array}$ & $\begin{array}{l}\text { KPS } \\
(\%)\end{array}$ & $\begin{array}{c}\text { KPS at } \\
\text { discharge }\end{array}$ & $\begin{array}{c}\text { Outcome } \\
\text { (follow up) }\end{array}$ & $\begin{array}{c}\text { Preoperative } \\
\text { neurological } \\
\text { findings } \\
\end{array}$ & $\begin{array}{l}\text { Improved } \\
\text { sign }\end{array}$ & $\begin{array}{l}\text { Neurological } \\
\text { deterioration }\end{array}$ & $\begin{array}{l}\text { Changes in vital } \\
\text { sign }\end{array}$ \\
\hline 1 & $55 \mathrm{~F}$ & Medulla & Total & 70 & 90 & $\begin{array}{l}\text { Good course } \\
\text { (79 Months) }\end{array}$ & $\begin{array}{c}\text { IX, X, } \\
\text { Cerebellar, } \\
\text { Sensory, MLF }\end{array}$ & $\begin{array}{l}\text { IX, MLF, } \\
\text { Cerebellar }\end{array}$ & None & $\begin{array}{c}\text { Bradycardia, } \\
\text { Hyperventilation }\end{array}$ \\
\hline 2 & $27 \mathrm{~F}$ & Midbrain & Total & 90 & 90 & $\begin{array}{l}\text { Good course } \\
\text { (127 Months) }\end{array}$ & $\begin{array}{c}\text { Homonymous } \\
\text { Hemianopsia, } \\
\text { Ataxia }\end{array}$ & Homonymous & $\begin{array}{l}\text { III (Transient), } \\
\text { II }\end{array}$ & None \\
\hline 3 & $66 \mathrm{~F}$ & $\begin{array}{l}\text { Midbrain-to } \\
\text { vermis }\end{array}$ & Total & 80 & 80 & $\begin{array}{l}\text { Good course } \\
\text { (163 Months) }\end{array}$ & Cerebellar & None & $\begin{array}{l}\text { Cerebellar } \\
\text { (Transient) }\end{array}$ & None \\
\hline 4 & $61 \mathrm{~F}$ & Medulla & Total & 90 & 90 & $\begin{array}{l}\text { Good course } \\
\text { (6 Months) }\end{array}$ & IX, X & None & None & $\begin{array}{c}\text { Bradycardia, } \\
\text { Hyperventilation }\end{array}$ \\
\hline 5 & $49 \mathrm{M}$ & Pons & Subtotal & 60 & 80 & $\begin{array}{l}\text { Good course } \\
\text { (30 Months) }\end{array}$ & $\begin{array}{l}\text { VII, VIII, } \\
\text { Cerebellar }\end{array}$ & $\begin{array}{c}\text { VII, } \\
\text { Cerebellar }\end{array}$ & None & None \\
\hline 6 & $58 \mathrm{~F}$ & Midbrain & Subtotal & 70 & 60 & $\begin{array}{l}\text { Motor weakness } \\
\text { (179 Months) }\end{array}$ & $\begin{array}{c}\text { V, VII, } \\
\text { Cerebellar, } \\
\text { Motor, } \\
\text { Dysarthria, MLF }\end{array}$ & None & $\begin{array}{l}\text { III, VII, XII, } \\
\text { Motor }\end{array}$ & None \\
\hline 7 & $53 \mathrm{M}$ & Pons & Partial & 80 & 60 & $\begin{array}{c}\text { Rebleeding } \\
\text { (2 Months), Dead }\end{array}$ & $\begin{array}{l}\text { Gaze palsy, } \\
\text { Motor, Sensory }\end{array}$ & None & $\begin{array}{l}\text { VII, Cerebellar, } \\
\text { Gaze palsy }\end{array}$ & None \\
\hline 8 & $67 \mathrm{M}$ & Pons & Partial & 50 & 50 & $\begin{array}{c}\text { Rebleeding } \\
\text { (14,16 Months), } \\
\text { Dead }\end{array}$ & $\begin{array}{l}\text { Gaze palsy, VII, } \\
\text { VIII, Ataxia }\end{array}$ & None & $\begin{array}{l}\text { VII (VII, VIII, } \\
\text { IX) }\end{array}$ & Atrial Flutter \\
\hline
\end{tabular}

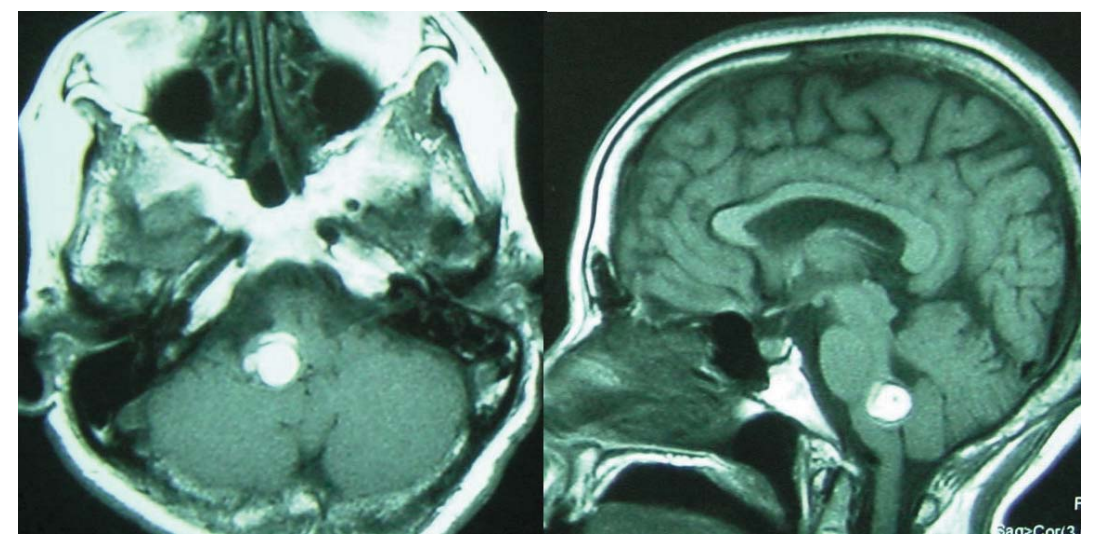

(a)

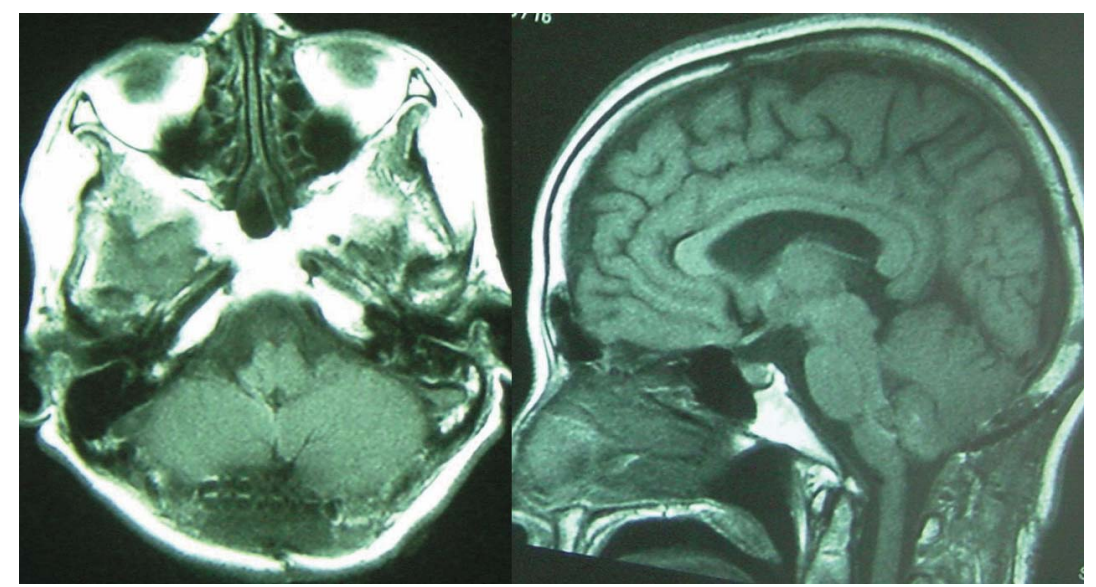

(b)

Figure 1. Cavernous angioma of the medulla oblongata. Preoperative and postoperative MRI (A and B). The patient underwent total removal of the lesion and showed marked resolution of preoperative swallowing disturbance, cerebellar symptoms and MLF immediately after the operation. 
including oculomotor nerve palsy and cerebellar signs, before making a complete recovery. One patient who underwent subtotal removal of the mass showed permanent exacerbation of motor weakness. Two patients who underwent partial removal of the lesions suffered worsening of facial palsy and hearing impairment, and impairment of PPRF. Intraoperative and postoperative pulmonary and circulatory symptoms occurred temporarily in three patients. Three patients had intraoperative bradycardia, postoperative atrial flutter two days after the operation, or hyperventilation. Intraoperative bradycardia occurred especially when the mass was pulled away from the brainstem. The bradycardia immediately disappeared after temporary cessation of the surgical procedure. Digitalis was administrated to the patients with atrial flutter, which occurred two days after the operation. Hyperventilation, which occurred one day after the operation, was resolved without treatment.

\section{Discussion}

For cavernous angiomas, radical extirpation is important, and inadequate excision results in recurrence of hemorrhage. As shown in the present study, inadequate excision was also related to postoperative deficits. Strong adhesion of a lesion to the brainstem may be associated with inadequate excision and postoperative deterioration. Patients who underwent total removal of cavernous angioma showed slight neurological deterioration after surgery. Total removal of the lesion is mandatory while conducting precise monitoring of circulation and respiration, both intraoperative and postoperatively. Overall, the evidence suggests that ocular symptoms are unlikely to be resolved. Monitoring of the abducens nerve may be one approach for preventing this problem, and this was done in one of our patients. Intraoperative bradycardia can occur especially when the mass was pulled away from the brainstem. Careful monitoring is mandatory for two or three days after operation to detect atrial flutter or other pulmonary disease.

\section{Conclusion}

We have described neurological changes after surgery in cases of brainstem cavernous angioma. As recovery from ocular symptoms is unlikely, intraoperative extraocular monitoring is mandatory when the lesion is close to the PPRF or MLF and the abducens nerve. In cases of cavernous angioma, inadequate excision results in not only recurrence of hemorrhage, but also postoperative neurological deterioration. Bradycardia can occur during the surgical intervention intraoperatively, and careful monitoring are mandatory for two or three days after operation to detect atrial flutter or other pulmonary disease.

\section{REFERENCES}

[1] R. W. Porter, P. W. Detwiler, R. F. Spetzler, M. T. Lawton, J. J. Baskin, P. T. Derksen and J. M. Zabramski, "Cavernous Malformation of the Brainstem: Experience with 100 Patients," Journal of Neurosurgery, Vol. 90, No. 1, 1999, pp. 50-58. doi:10.3171/jns.1999.90.1.0050

[2] K. Kikuta, K. Nozaki, J. A. Takahashi, S. Miyamoto, H. Kikuchi and N. Hashimoto, "Postoperative Evaluation of Microsurgical Resection for Cavernous Malformations of the Brainstem,” Journal of Neurosurgery, Vol. 101, No. 4, 2004, pp. 607-612. doi:10.3171/jns.2004.101.4.0607 